\section{Improving Growth of Calibrachoa in Hanging Flower Pouches}

\author{
Jonathan M. Frantz ${ }^{1,3}$, James C. Locke ${ }^{1}$, and \\ Dharmalingam S. Pitchay ${ }^{2}$
}

ADDITIONAL INDEX WORDs. floriculture, container geometry, substrate, potting mix, SPAD, chlorophyll content, hydrogel, water distribution, chlorosis, Calibrachoa $\times$ bybrida

Summary. Unique growing containers and nontraditional types of plant presentation may lead to new production problems for growers. This study was conducted to evaluate the growth of a popular container plant, calibrachoa (Calibrachoa $\times$ bybrida), produced in hanging flower pouches using different growing substrate compositions, polymer amendments, and the layering of substrate types of differing moisture holding capacity with the goal of achieving more uniform plant growth and improved after-sale maintenance. Plastic cylindrical hanging pouches were filled with one of nine hydrated substrate types or combinations. Rooted cuttings of 'Colorburst Violet' calibrachoa were planted as indicator plants to identify treatment effects because of their susceptibility to iron deficiency-induced chlorosis of new leaves. Daily measurements of substrate moisture were taken to determine the need for irrigation. Chlorophyll content was estimated nondestructively with a hand-held chlorophyll meter to determine the impact of moisture content. Light, porous substrates resulted in the most uniformly green plants and high numbers of flowers from top to bottom. A layered pouch with heavy, compost-amended substrate above a light, porous layer also produced high-quality, uniform plants. This enabled water to be distributed more uniformly throughout the container volume. This study provides fundamental information on how container geometry and soil moisture retention can influence water management decisions by the grower.

$\mathrm{T}$ The value of floriculture crops has risen in each of the last 10 years (U.S. Department of Agriculture, 2005). New crops, better cultivars, and improved marketing have all contributed to this increase. Recently, a novel floriculture hanging container was introduced: long, plastic, substrate-filled pouches with planter holes along one side and the top. Retailing for US\$15 to US\$30 each, consumers purchase these to hang on fence posts, walls, and doors, with plants cascading over and down the sides of the pouches (Fig. lA).

${ }^{1}$ USDA-ARS, 2801 W. Bancroft, Mail Stop 604, Toledo, OH 43606

${ }^{2}$ Department of Biological Sciences, The University of Toledo, 2801 W. Bancroft, Mail Stop 601, Toledo, OH, 43606

Mention of a trademark, proprietary product, or vendor does not constitute a guarantee or warranty of the product by the U.S. Department of Agriculture and does not imply its approval to the exclusion of other products or vendors that also may be suitable.

We thank Leona Horst, Ann Widrig, and Tom Creque for their helpful comments, and the members of the Toledo Area Flower \& Vegetable Growers Association for their useful feedback on this project.

${ }^{3}$ Corresponding author. E-mail: jonathan.frantz@ utoledo.edu
Even though these hanging pouches sell well, the unique container can pose production problems for growers. Container geometry (Fonteno, 1996), substrate water holding capacity and irrigation needs (Handreck and Black, 2002a), and individual grower's tendencies to over- or underwater lead to uneven plant growth (Fig. 1B-D). The substrate stays wetter at the bottom of the pouch so that if the pouches are watered based on the moisture level at the top of the pouch, the plants at the bottom will be stunted (Fig. IC). If the pouch is watered based on the bottom plants, the top plants will be stunted resulting from dry substrate (Liptay et al., 1998) (Fig. 1B). Even if the plants grow out of the stunting, asymmetrical growth and flower development can lead to "top-heavy" flowering pouches (Fig. 1C, D).

Increasing the complexity of the problem is many growers' desire to water less frequently or to provide longer time between irrigations for consumers through different substrate selection or amendments (Frantz et al., 2005). As a result, heavier substrates (substrates with greater water holding capacity) supplemented with compost or hydrogel are being used for pouches.

The purpose of this study was to evaluate plant growth in hanging pouches using different commercially available and polymer-supplemented substrates. We also investigated the possibility of layering the root zone with different substrate types to make the water retention properties in the profile more uniform for production (Henry et al., 2006) and to provide lengthened shelf-life between irrigations.

\section{Materials and methods}

Plastic cylindrical hanging pouches (Al's Flower Pouches; AMA Plastics Ltd., Ont., Canada) with a volume of $16.4 \mathrm{~L}$ (20 inches tall $\times$ 8 inches wide) were filled with one of nine hydrated substrate types or combinations (Table $\mathrm{l}$ ) classified either as single mixes, polymer amended, or layered. Control, polymer-amended treatments, and the first two layered treatments were made from sphagnum peat (BP-P; Berger Peat Moss, Ltd., Quebec) and medium horticultural-grade perlite (Whittemore Co., Lawrence, Mass.). The porous and compost mixes were obtained commercially (BM6 and BM8, respectively; Berger Peat Moss, Ltd.). A polyacrylamide-based, water-absorbing polymer (Soil Moist; JRM Chemical, Inc., Cleveland) was used in the polymer-amended treatments.

The substrate was initially hydrated to runoff and was allowed to stop dripping before filling the pouches. A typical grower does not normally

\begin{tabular}{llll}
\hline $\begin{array}{l}\text { Units } \\
\text { To convert U.S. to SI, } \\
\text { multiply by }\end{array}$ & U.S. unit & SI unit & $\begin{array}{l}\text { To convert SI to U.S., } \\
\text { multiply by }\end{array}$ \\
\hline 38.6807 & $\mathrm{fl} \mathrm{oz} / \mathrm{yard} 3$ & $\mathrm{~mL} \cdot \mathrm{m}^{-3}$ & 0.0259 \\
3.7854 & gal & $\mathrm{L}$ & 0.2642 \\
2.5400 & inch $(\mathrm{es})$ & $\mathrm{cm}$ & 0.3937 \\
28.3495 & $\mathrm{oz}$ & $\mathrm{g}$ & 0.0353 \\
$\left({ }^{\circ} \mathrm{F}-32\right) \div 1.8$ & ${ }^{\circ} \mathrm{F}$ & ${ }^{\circ} \mathrm{C}$ & $\left(1.8 \times{ }^{\circ} \mathrm{C}\right)+32$
\end{tabular}



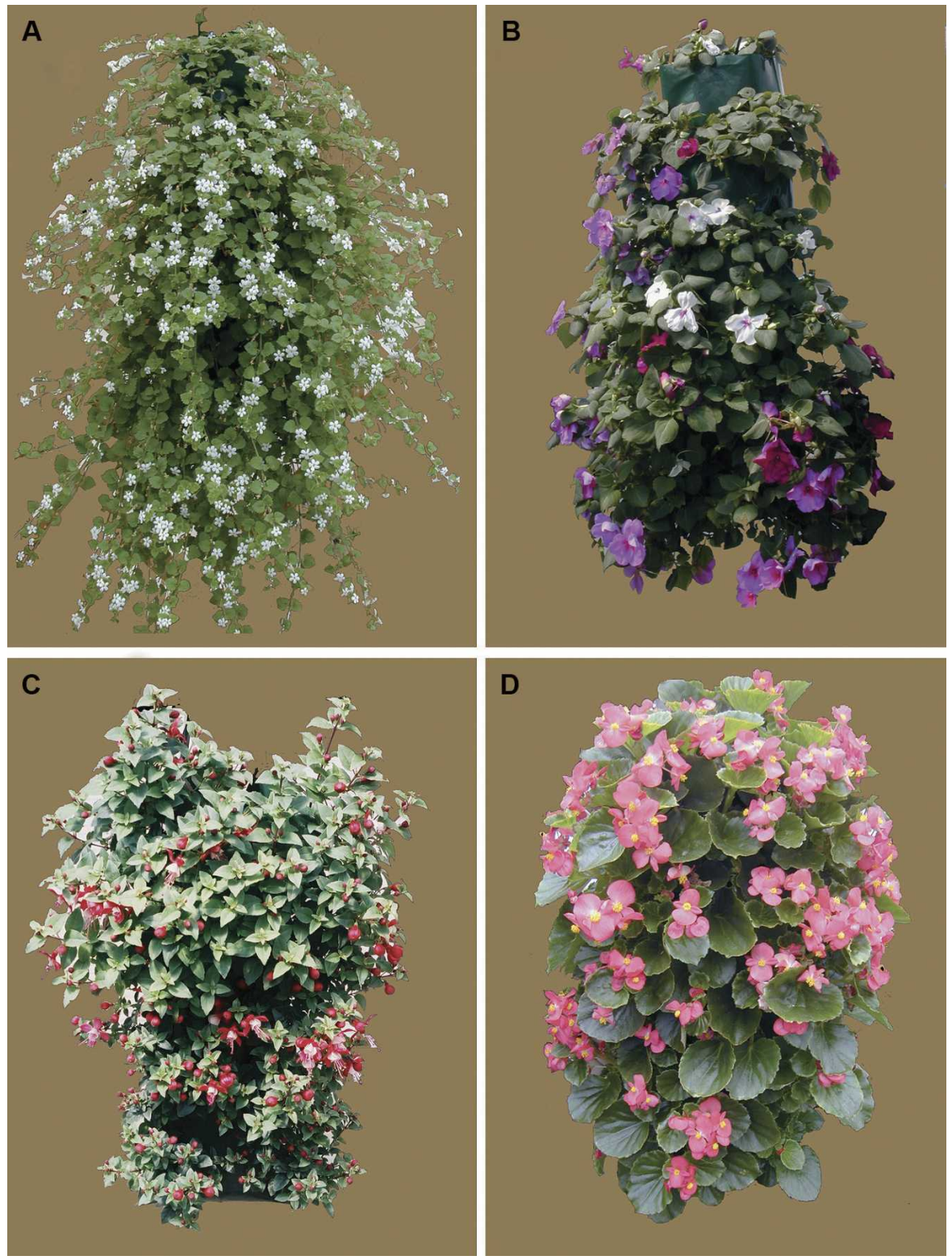

Fig. 1. (A-D) Normal, well-proportioned bacopa (Sutera cordata) in a hanging pouch (A); bottom-heavy impatiens (Impatiens wallevana) grown with stunted top plants (B); fuschia (Fuschia $\times$ bybrida) with lower plants stunted, likely from water stress $(\mathrm{C})$; and begonia (Begonia $\times$ semperflorens) plants showing similar stunting in the lower plants (D). hydrate all substrate before planting. However, because some of the treatments contained a hydrophilic polymer, hydrating all the substrates to maximum water holding capacity before planting enabled more uniform experimental conditions at the start of the experiment regardless of substrate amendments. A wetting agent [150 $\mathrm{mL} \cdot \mathrm{m}^{-3}$ (Soax; Smithers-Oasis, Kent, Ohio)] was added to the substrate before hydrating because some of the experimental substrates differed in age, and the wetting agent added by the commercial supplier may have broken down during storage (Handreck and Black, 2002b). A substrate of 70 peat: 30 perlite (by volume) was used as a control for comparison with all other substrate types.

After filling, the pouches were laid lengthwise on benches and planted with rooted cuttings of calibrachoa. Calibrachoa was chosen because it is a popular container plant with a trailing growth habit that suits hanging pouch production. It also provides an easy way to diagnose or identify treatment effects rapidly and visually because of its susceptibility to iron deficiency-induced chlorosis of new leaves when overwatered (Fischer et al., 2003). Cuttings were made from stock plants originally obtained from the Paul Ecke Ranch (Encinitas, Calif.) and were rooted in-house to minimize any potential unknown growth-regulating effects from a commercial producer. The rooted cuttings were pinched when placed in the rooting station and were grown for $\approx 2$ weeks. After 2 weeks, the plants were $25 \mathrm{~cm}$ tall. Each pouch received 10 plants in five groups consisting of the bottom four

Table 1. List of substrate types and substrate treatments used in this study.

\begin{tabular}{ll}
\hline Substrate type & \multicolumn{1}{c}{ Substrate treatment } \\
\hline Single mixes & Control: $70 \%$ peat, 30\% perlite \\
& Porous: $78 \%$ peat, $22 \%$ perlite \\
Polymer amended & Compost: $75 \%$ peat, $13 \%$ perlite, $5 \%$ vermiculite, $7 \%$ compost \\
& $58.4 \%$ peat, $25 \%$ perlite, $16.6 \%$ polymer amended $($ by volume $)$ \\
Layered & $49.8 \%$ peat, $21.4 \%$ perlite, $28.8 \%$ polymer amended $($ by volume $)$ \\
& Three layers of peat and perlite respectively: $70: 30 / 60: 40 / 50: 50$ \\
& Three layers of peat and perlite respectively: $80: 20 / 70: 30 / 60: 40$ \\
& Two layers: porous on top and compost on bottom \\
\hline
\end{tabular}

Control, polymer-amended treatments, and the first two layered treatments were made from sphagnum peat (BP-P; Berger Peat Moss, Ltd. Que., Canada) and medium horticultural-grade perlite (Whittemore Co., Lawrence, Mass.). The porous and compost mixes were obtained commercially (BM6 and BM8, respectively; Berger Peat Moss, Ltd.). A polyacrylamide-based, water-absorbing polymer (Soil Moist; JRM Chemical, Cleveland) was used in the polymer-amended treatments. In the layered treatments, a slash (/) indicates a layer separation. 
Table 2. Mean chlorophyll soil-plant analysis development (SPAD) values $(n=16)$ for fully expanded leaves of calibrachoa at the top or bottom of the hanging pouches.

\begin{tabular}{lcr}
\hline & \multicolumn{2}{c}{ SPAD value (mean \pm SE) } \\
\cline { 2 - 3 } Substrate type & \multicolumn{1}{c}{ Top } & Bottom \\
\hline Single mixes & $34.2 \pm 0.6$ & $11.6 \pm 1.5$ \\
$\quad$ Control & $39.2 \pm 0.5$ & $31.4 \pm 0.6$ \\
$\quad$ Porous & $36.0 \pm 0.9$ & $17.2 \pm 0.9$ \\
$\quad$ Compost & & \\
Polymer amended & $35.4 \pm 0.7$ & $12.2 \pm 2.3$ \\
16.6\% polymer & $36.4 \pm 0.6$ & $18.4 \pm 1.8$ \\
28.8\% polymer & & \\
Layered & $37.3 \pm 0.7$ & $13.9 \pm 2.1$ \\
$\quad 70 \%: 60 \%: 50 \%$ & $35.9 \pm 0.5$ & $14.6 \pm 2.0$ \\
$\quad 80 \%: 70 \%: 60 \%$ & $37.0 \pm 1.5$ & $21.0 \pm 1.8$ \\
$\quad$ Porous:compost & $37.2 \pm 0.7$ & $33.4 \pm 1.4$ \\
$\quad$ Compost:porous & & \\
\hline
\end{tabular}

Leaves appear yellow or chlorotic when soil-plant analysis development (SPAD) values are lower than $\approx 25$ (pers. obs.). Control mix is a $70 \%$ peat-to- $30 \%$ perlite mixture, whereas porous and compost mixes are commercial blends of peat and perlite with or without vermiculite and compost. For the polymer-amended treatments, the labels $16.6 \%$ and $28.8 \%$ indicate a mixture of $58.4 \%$ peat, $25 \%$ perlite, and $16.6 \%$ hydrophilic polymer or $49.8 \%$ peat, $21.4 \%$ perlite, and $28.8 \%$ hydrophilic polymer (by volume). The layered treatment values indicate the amount of peat in each layer with the remainder made of perlite or a layering of the two commercial mixes.

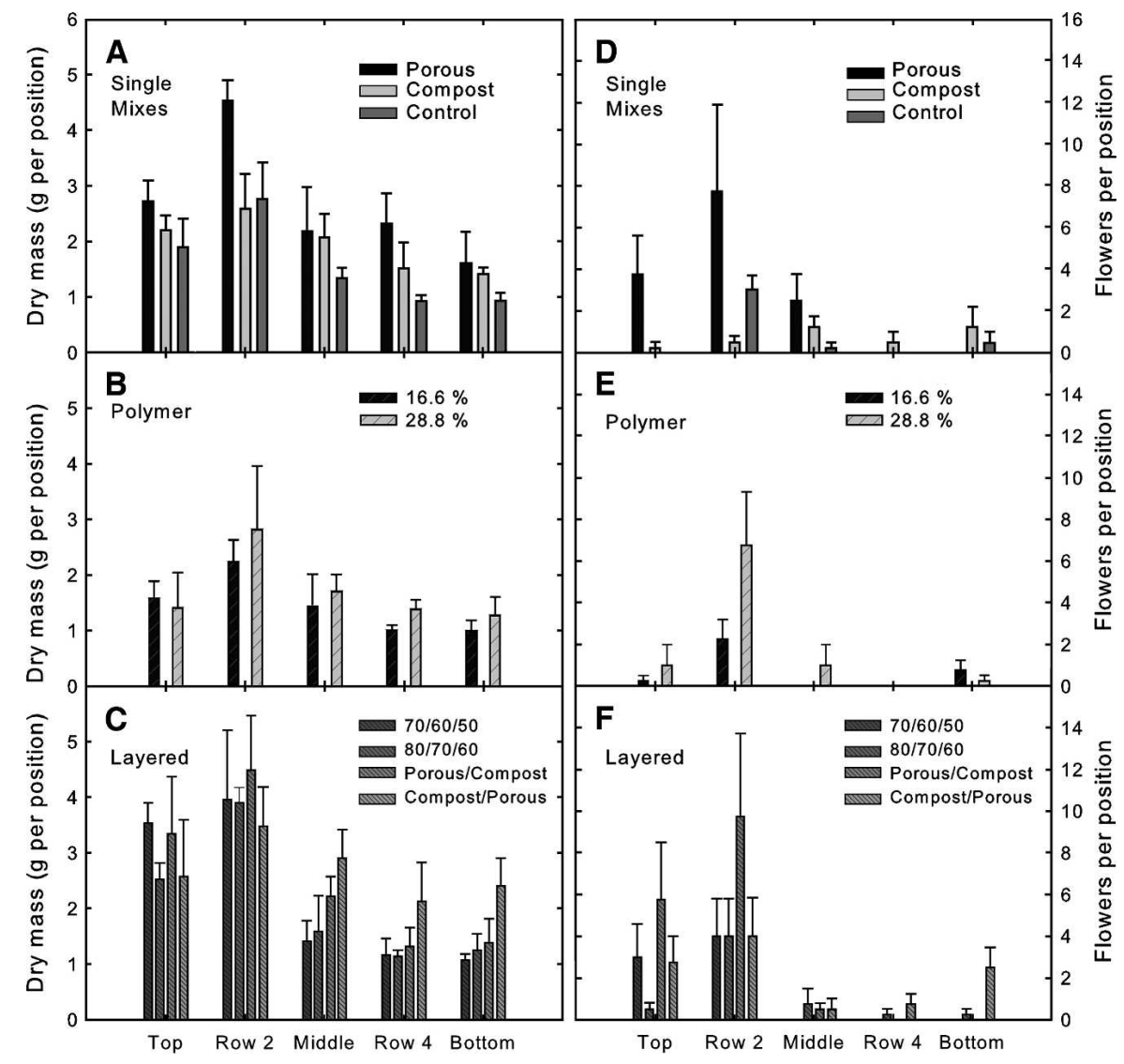

Fig. 2. (A-F) Average dry weight (A-C) and flower number (D-F) of calibrachoa for each plant row in the hanging pouch, grouped in single-mix $(A$ and $D)$, polymeramended ( $\mathrm{B}$ and $\mathrm{E})$, and layered treatments $(\mathrm{C}$ and $\mathrm{F})$. Control $\mathrm{mix}$ is a $70 \%$ peatto- $30 \%$ perlite mixture, whereas porous and compost mixes are commercial blends of peat and perlite with or without vermiculite and compost. For the polymeramended treatments, the labels $\mathbf{1 6 . 6 \%}$ and $28.8 \%$ indicate a mixture of $58.4 \%$ peat, $25 \%$ perlite, and $16.6 \%$ hydrophilic polymer or $49.8 \%$ peat, $21.4 \%$ perlite, and $\mathbf{2 8 . 8} \%$ hydrophilic polymer (by volume). The layered treatment values indicate the amount of peat in each layer with the remainder made of perlite or a layering of the two commercial mixes. Error bars are $\pm 1 \mathrm{SE} .1 \mathrm{~g}=\mathbf{0 . 0 3 5 3} \mathrm{oz}$. rows and the pouch opening at the top. The top row of the pouch was not planted because of anticipated settling of the substrate after the pouch was hung and for the duration of the 4 -week study. Four replicate pouches were used for each treatment and were arranged in a randomized complete block design. The newly transplanted plants were allowed to grow for l week before hanging the pouches along the south wall of a greenhouse.

The greenhouse was maintained at $27 / 22^{\circ} \mathrm{C}$ day/night and the crop was grown from 26 Mar. 2004 to 23 Apr. 2004. Daily measurements of substrate moisture content were made in the top, middle $(25 \mathrm{~cm}$ from the top), and bottom (45 cm from the top) of the pouches using a substrate moisture probe (Theta Probe; Delta-T Devices, Cambridge, UK). The millivolt output for the moisture probes was converted to volumetric moisture content (percent) with the factory-calibration, third-order equation for organic soil. Growers have indicated that they irrigate based on the weight of the pouch, by the appearance of the substrate at the top of the pouch, or a combination of approaches. Because there was not a quantitative measure of how growers approach irrigation of pouches, pouches were irrigated when moisture levels in two or more pouches from each treatment fell below a set point of $23 \%$ moisture at the middle measuring point to reduce extreme moisture conditions in the top or bottom of the pouches. Chlorophyll content was estimated nondestructively three times with a hand-held chlorophyll meter (SPAD-502; Minolta Camera Co., Ltd., Tokyo) using four mature leaves from the top row and bottom row of plants on each of the four replicate pouches of each treatment.

After 4 weeks, the plants were harvested by cutting the stem at the substrate surface. Flowers per row of plants were counted and the shoot was placed in a paper pouch, dried in a forced air oven at $65^{\circ} \mathrm{C}$ for $2 \mathrm{~d}$, and weighed. The substrate shrinkage or compaction was determined by measuring the distance from the top of the pouch to the top of the substrate.

For chlorophyll content, a threeway analysis of variance (ANOVA) was run, with treatment, position, and date being the primary factors 
Table 3. Average dry weight and flower number of calibrachoa per hanging pouch $(n=4)$.

\begin{tabular}{lrr}
\hline Substrate type & $\begin{array}{c}\text { Average dry wt } \pm \text { SE } \\
(\mathbf{g} / \text { pouch })^{\mathrm{z}}\end{array}$ & $\begin{array}{c}\text { Average flowers } \pm \mathrm{SE} \\
(\mathbf{n} / \text { pouch })\end{array}$ \\
\hline Single mixes & $7.9 \pm 0.7$ & \\
$\quad$ Control & $13.4 \pm 0.5$ & $3.8 \pm 1.1$ \\
$\quad \begin{array}{l}\text { Porous } \\
\quad \text { Compost }\end{array}$ & $9.8 \pm 0.6$ & $14.0 \pm 5.4$ \\
Polymer amended & $7.2 \pm 0.6$ & $3.8 \pm 0.5$ \\
$\quad$ 16.6\% polymer & $8.6 \pm 0.7$ & $3.3 \pm 0.8$ \\
28.8\% polymer & $11.1 \pm 0.7$ & $9.0 \pm 3.5$ \\
Layered & $10.4 \pm 0.5$ & $7.0 \pm 3.3$ \\
$\quad 70 \%: 60 \%: 50 \%$ & $12.7 \pm 1.4$ & $5.8 \pm 1.9$ \\
80\%:70\%:60\% & $13.5 \pm 1.1$ & $16.0 \pm 6.9$ \\
$\quad$ Porous:compost & & $10.5 \pm 3.1$ \\
$\quad$ Compost:porous & & \\
\hline
\end{tabular}

\section{${ }^{\mathrm{z}} 1 \mathrm{~g}=0.0353 \mathrm{oz}$}

Control mix is a $70 \%$ peat-to- $30 \%$ perlite mixture, whereas porous and compost mixes are commercial blends of peat and perlite with or without vermiculite and compost. For the polymer-amended treatments, the labels $16.6 \%$ and $28.8 \%$ indicate a mixture of $58.4 \%$ peat, $25 \%$ perlite, and $16.6 \%$ hydrophilic polymer or $49.8 \%$ peat, $21.4 \%$ perlite, and $28.8 \%$ hydrophilic polymer (by volume). The layered treatment values indicate the amount of peat in each layer with the remainder are made of perlite or a layering of the two commercial mixes. Porous substrates and layered treatments tended to have larger plants with more flowers compared with other treatments. Polymeramended substrates produced small, stunted plants with few flowers. within each of the three substrate types. For flower numbers and shoot dry weight, a two-way ANOVA was run, with treatment and row as the primary factors. Shrinkage differences between treatments were determined with a one-way ANOVA. In the event that the one-way ANOVA determined differences between the main effects $(P<0.05)$, Tukey's pairwise test of means was used to determine which main effects differed $(P<0.05)$.

\section{Results and discussion}

Chlorophyll. The plants appeared similar after 1 week of establishment when they were hung into the treatment groups. However, the treatments quickly began showing differences in chlorophyll 7 to $10 \mathrm{~d}$ after hanging (Table 2). No further differences in chlorophyll became evident in time $(P=0.082)$, so only the
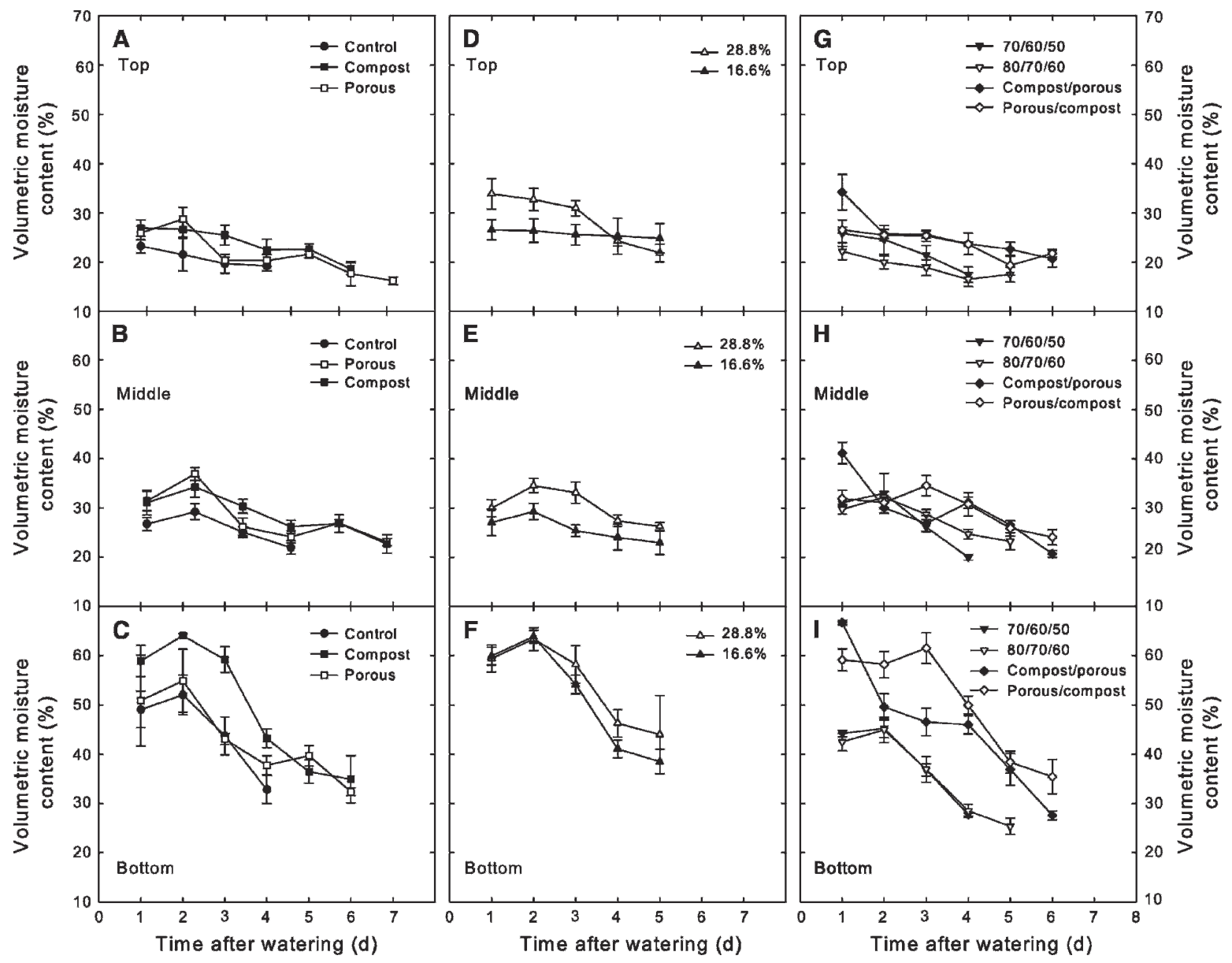

Fig. 3. (A-I) Volumetric moisture content (measured as a percentage) during one wet-to-dry cycle, measured at three locations along the length of the pouch (top, middle, and bottom) in the single-mix (A-C), polymer-amended (D-F), and layered treatments $(\mathrm{G}-\mathrm{I})$ during calibrachoa growth. Control mix is a $70 \%$ peat-to-30\% perlite mixture, whereas porous and compost mixes are commercial blends of peat and perlite with or without vermiculite and compost. For the polymer-amended treatments, the labels $16.6 \%$ and $28.8 \%$ indicate a mixture of $58.4 \%$ peat, $25 \%$ perlite, and $16.6 \%$ hydrophilic polymer or $49.8 \%$ peat, $21.4 \%$ perlite, and $28.8 \%$ hydrophilic polymer (by volume). The layered treatment values indicate the amount of peat in each layer with the remainder made of perlite or a layering of the two commercial mixes. Error bars are \pm 1 SE. 
final chlorophyll measurements are presented.

Within the single-mix group, the porous substrate resulted in the most uniformly green plants whereas the other two treatments in this group had significantly less chlorophyll at the bottom of the pouch. Both polymer-amended treatments had less chlorophyll in the lower plants than the upper plants. The compost-overporous mixture had more chlorophyll in the lower plants than the lower plants in the other layered treatments. Because the compost-amended substrate is reported to have greater water holding capacity (Berger Peat Moss, Ltd., 2002), and was placed at the top of the pouch, this layered treatment was predicted to be the best for moisture distribution throughout the pouch. Putting the "heavier" substrate at the lower layer, (porous-overcompost mixture) was expected to be a "worse-case" scenario for water uniformity. This treatment did result in nonuniform chlorophyll.

Growth AND Flowering. Plants were larger toward the top of each pouch in each treatment and contained more flowers on those plants (Fig. 2, Table 3). This led to the appearance of "top-heavy" growth for each of the pouches. In the single mixes, the porous substrate had larger plants in the second row than the control and compost-based mix (Fig. 2A). There was no difference in the dry weight for the polymer treatments (Fig. 2B). The compost/ porous treatment resulted in the most uniformly large plants from top to bottom, yet did not have the largest plants in row 2 when compared with the other layered treatments (Fig. 2C). By layering substrate from heavy, greater water holding capacity in the top of the pouch to porous substrate on the bottom, uniformly large, green plants could be produced.

The porous, single-mix treatment had more flowers than the compost treatment or control (Table 3 ), but most flowers were located in the first and second rows (Fig. 2D). The $28.8 \%$ polymer-amended treatment had more flowers in row 2 than the $16.6 \%$ treatment (Table 3, Fig. 2E). Surprisingly, there were more flowers in the porous/compost treatment in the top two rows than the other layered treatments, even though this was designed to be a worse-case scenario for water distribution (Fig. $2 \mathrm{~F})$. That treatment did have greater variability than the other layered treatments (Table 3). The compostover-porous substrate had more flowers at the bottom of the pouch than other treatments, resulting in a pouch that appeared to have many flowers uniformly distributed from top to bottom, which is an important characteristic for sale of this product.

WATERING AND COMPACTION. Only one wet/dry cycle for each treatment is shown for simplicity, but it illustrates the variance in moisture content each day at each level (Fig. 3 ). The tops of each pouch generally had the lowest moisture content of the three measuring locations and did not change in magnitude as much as the other two locations, as expected (Fonteno, 1996). The second day after wetting often had higher average moisture for the middle and lower locations, suggesting the substrates were not uniformly wet shortly after watering, but required $\mathrm{l} d$ to equilibrate. A wetting agent was not used during the irrigation cycles but was incorporated with the peat in each of the substrate types.

There was minimal compaction in all treatments except the polymeramended treatments (Fig. 4). This is similar to what was observed in hanging baskets with New Guinea impatiens (Impatiens hawkeri) (Frantz et al., 2005) and, because of this, adding polymer to the substrate for hanging pouches would not be recommended unless the substrate is topped off after hanging the pouches. If this is done, however, the plants located at the pouch opening must be planted significantly later than the other plants, which may result in uneven form of the plants. Settling and channeling of irrigations was not noticed in any of the treatments throughout the study.

As long as consumers demand new products and the new products sell, growers will be faced with adapting horticultural approaches to fit the new products. Pouches have advantages in production because they can be hung on greenhouse walls or walkways, thereby increasing the space use efficiency of greenhouse space. Hanging pouches provide a lesson in how container geometry and soil moisture retention properties can influence the decisions on appropriate management

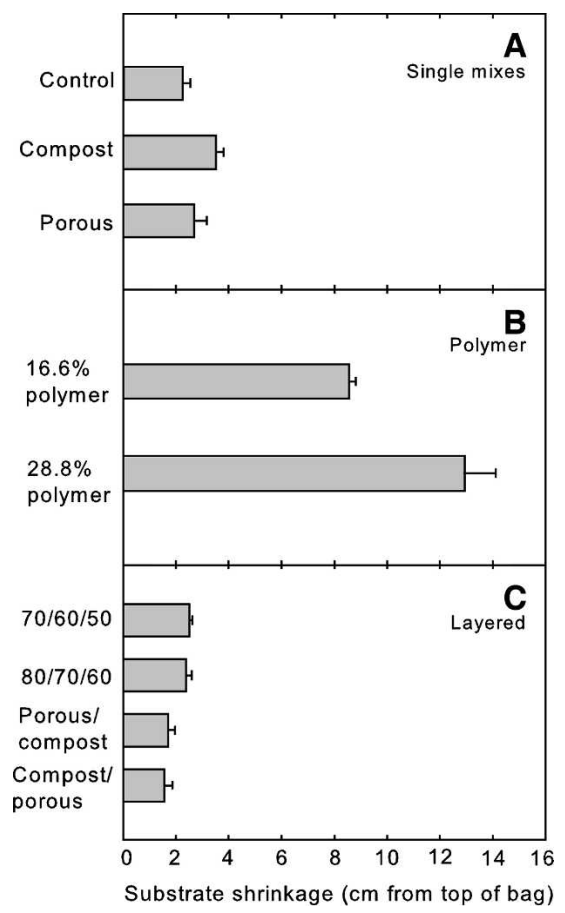

Fig. 4. (A-C) Substrate shrinkage or settling from the top of the pouch opening of hanging pouches after 4 weeks of calibrachoa growth of singlemix (A), polymer-amended (B), and layered treatments $(\mathrm{C})$. Control mix is a $70 \%$ peat-to- $30 \%$ perlite mixture, whereas porous and compost mixes are commercial blends of peat and perlite with or without vermiculite and compost. For the polymer-amended treatments, the labels $16.6 \%$ and $28.8 \%$ indicate a mixture of $58.4 \%$ peat, $25 \%$ perlite, and $16.6 \%$ hydrophilic polymer or $49.8 \%$ peat, $21.4 \%$ perlite, and $28.8 \%$ hydrophilic polymer (by volume). The layered treatment values indicate the amount of peat in each layer with the remainder made of perlite or a layering of the two commercial mixes. In the layered treatments, a slash $(/)$ indicates a layer separation. Error bars are $\pm 1 \mathrm{SE}$. $1 \mathrm{~cm}=0.3937$ inch .

practices. In this case, the ideal substrates were commercially available "porous" mixes or a combination of a heavier, water holding substrate on top of a porous mix, which served to distribute the water uniformly throughout the container volume (Fig. 3). For calibrachoa, this resulted in a uniformly green plant (Table 2) that contained flowers predominately at the top rows of the pouches, with some flowers in the lower portion of the pouches (Fig. 2). Adding heavier substrate or water-absorbing polymer to reduce watering frequency did not improve plant quality (Table 3 ) and 


\section{Research Reports}

caused substantial shrinkage or compaction (Fig. 4). As always, there are species-specific fixes that can eliminate symptoms of stress for sale, including feeding iron chelate to calibrachoa to mask chlorosis incited by other factors (Fischer et al., 2003). When those quick fixes are used in combination with a fundamental understanding of why the symptoms appear and persist, a larger variety of crops can be grown in the containers that the market demands, and will continue to increase the value of the floriculture and ornamental industry in the years to come.

\section{Literature cited}

Berger Peat Moss Ltd. 2002. BM-8 (composted peat mix): Technical data. 11 May 2006. <www.bergerweb.com/en/ bm8.php $>$.
Fischer, P., R.M. Wik, B.R. Smith, C.C. Pasian, M. Kmetz-González, and W.R. Agro. 2003. Correcting iron deficiency in calibrachoa grown in a container medium in high $\mathrm{pH}$. HortTechnology 13:308-313.

Fonteno, W.C. 1996. Growing media: Types and physical/chemical properties, p. 93-122. In: D.W. Reed (ed.). Water, media, and nutrition for greenhouse crops. Ball Publ., Batavia, Ill.

Frantz, J.M., J.C. Locke, D.S. Pitchay, and C.R. Krause. 2005. Actual performance versus theoretical advantages of polyacrylamide hydrogel throughout bedding plant production. HortScience 40:2040-2046.

Handreck, K. and N. Black. 2002a. Growing media and water, p. 64-78. In: K. Handreck and N. Black (eds.). Growing media for ornamental plants and turf. 3rd ed. University of New South Wales Press, Sydney.
Handreck, K. and N. Black. 2002b. Problems with organic materials, p. 30-43. In: K. Handreck and N. Black (eds.). Growing media for ornamental plants and turf. 3rd ed. University of New South Wales Press, Sydney.

Henry, A., W. Doucette, J. Norton, S. Jones, J. Chard, and B. Bugbee. 2006. An axenic plant culture system for optimal growth in long-term studies. J. Environ. Qual. 35:590-598.

Liptay, A., P. Sikkema, and W. Fonteno. 1998. Transplant growth control through water deficit stress: A review. HortTechnology 8:540-543.

U.S. Department of Agriculture. 2005. Floriculture crops: 2004 summary. U.S. Department of Agriculture, National Agricultural Statistics Service, Washington, D.C. 